\title{
Analysis of Group-buckling and -debonding Behaviors of Galvannealed Coating Layer on Steel Substrates under Applied Tensile Strain
}

\author{
Sohei IWAMOTO, ${ }^{1)}$ Shojiro OCHIAI' ${ }^{21}$ and Hiroshi OKUDA ${ }^{21}$ \\ 1) Graduate Student, Kyoto University, Yoshida, Sakyo-ku, Kyoto 606-8501 Japan. \\ 2) Graduate School of Engineering, Kyoto University, Yoshida, Sakyo-ku, Kyoto 606-8501 Japan.
}

(Received on September 9, 2008; accepted on October 29, 2008)

\begin{abstract}
The hot-dipped galvannealed steels are composed of brittle coating layer with low failure strain and ductile substrate with far higher failure strain. When tensile stress is applied externally on the coated steels, the coating layer exhibits multiple cracking perpendicular to the tensile direction, and then interfacial debonding occurs, following the buckling of the coating layer in the sample width direction. In the buckling behavior, the series of cracked-coating layers arraying along the tensile direction exhibit group-buckling. In the present work, the group-buckling behavior was observed with the scanning electron microscope and analyzed with 3-dimensional finite element models. It was observed that the preceding buckling of the coating enhances the buckling of the neighboring coating. Such a behavior was well accounted for by the present analysis.
\end{abstract}

KEY WORDS: finite element analysis; galvannealed steel; coating; cracking; buckling; spalling; interface.

\section{Introduction}

The hot-dipped GA (galvannealed) steels, consisting of $\mathrm{Fe}-\mathrm{Zn}$ intermetallic coating layer and substrate steel, are widely used as architectural and car-body materials due to their high corrosion resistance and weldability. ${ }^{1,2)}$ As these materials are composed of brittle coating layer with low failure strain and ductile substrate with far higher failure strain, the coating layer exhibits multiple cracking perpendicular to the tensile direction, ${ }^{3-8)}$ and then spalled when tensile stress is applied externally. The spalling of the coating layer is caused by the compressive stress-induced buckling in the sample width direction, ${ }^{7}$ followed by interfacial debonding. The SEM image and schematic representation of the buckling behavior of the GA coating layer in the sample used in this work under applied tensile strain are shown in Fig. 1. The details of the sample specification and the procedure for tensile test and fracture morphology observation will be shown later in Sec. 2.1.

In the buckling behavior, series of cracked-coating layers arraying along the tensile direction exhibit group-buckling as will be shown later in Fig. 4. However, the mechanism of such a group-buckling has not been revealed yet. In the present work, the group-buckling behavior was observed in detail with the scanning electron microscope and analyzed with 3-dimentional finite element models.

For analysis of the group-buckling behavior, the following cases, shown schematically in Fig. 2, were taken up. The coatings named coats (i), (ii) and (iii) are lined up in the tensile direction. When the bonding strength in the coating/substrate interfaces of each coating is equal (Case I in
Fig. 2), the debonding of the coating layer occurs at the same time. On the other hand, when the bonding strength in the coating/substrate interface of coat (ii) is weaker than those of coat (i) and (iii) (Case II in Fig. 2), the interfacial debonding of the coat (ii) occurs first. Under the condition that the coats (i) and (iii) have a common bonding strength in both Cases I and II, whether the group-bucking/debonding occurs or not can be judged by comparing the behavior of coat (i) and (iii) in Case I to those in Case II; when the debonding of coat (i) and (iii) for Case II are larger than those for Case I, the group-buckling should take place.

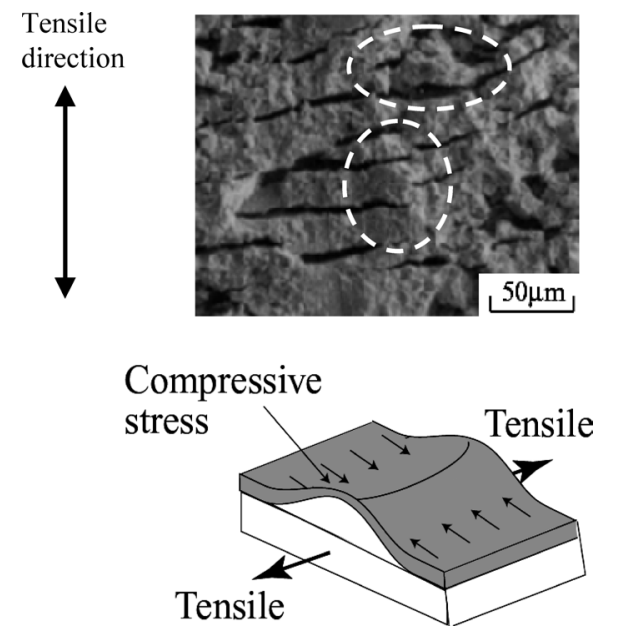

Fig. 1. SEM image and schematic representation of the buckling behavior of the coating layer. 


\section{Experimental Procedure}

\subsection{The Group-buckling Observation of the Coating Layer}

The used samples were the hot-dipped Fe-Zn intermetallic compound-coated IF (Interstitial Free) steels. These samples were supplied as the common samples for the research group on structure and property of the coating on GA (galvannealed) steels, organized in the Iron and Steel Institute of Japan. The overall thickness of the coating layer was $10 \mu \mathrm{m}$.

For tensile test, the samples with a length $100 \mathrm{~mm}$, width $10 \mathrm{~mm}$ and thickness $0.8 \mathrm{~mm}$ were prepared. Tensile test was carried out at room temperature at a crosshead speed of $8.3 \times 10^{-6} \mathrm{~m} / \mathrm{s}$. The strain for a gage length $50 \mathrm{~mm}$ was measured by the non-contact laser extensometer (Shimadzu DVE-200).

The measurement of the change of the crack spacing in the coating layer has been presented in our former work. ${ }^{9)}$ In the present work, compressive fracture and spalling behavior, especially the group-buckling, of the tensile-tested samples were carefully observed with the scanning electron microscope (Joel, JSM-5410LS).

\subsection{Finite Element Analysis}

3-Dimensional models for analysis of interfacial debonding of the coating layer were prepared as follows. The morphology of the specimen with multiple-cracked $\mathrm{Fe}-\mathrm{Zn}$ in-

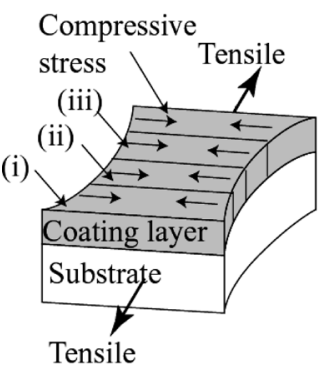

Case I

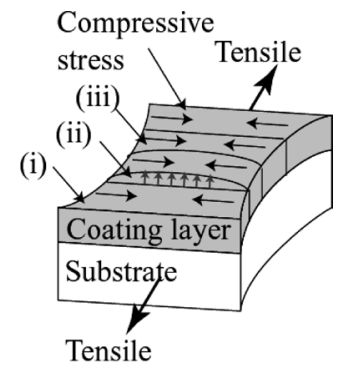

Case II
Fig. 2. Schematic representation of the cases employed for analysis of the group-buckling behavior. termetallic compound coating layer is schematically shown in Fig. 3(a) where $L$ is the crack spacing in the tensile direction, $W$ is the crack spacing in the width direction, $t$ is the thickness of the substrate steel and $T$ is the thickness of the coating layer. As indicated in Fig. 3(a), the longitudinal distance $x$ was taken to be zero at the middle, and to be $L / 2$ at the broken end. The distance $y$ in the width direction was taken to be zero at the broken end, to be $W / 2$ at the middle, and to be $W$ at the other broken end. The vertical distance $z$ was taken to be zero at the middle of substrate in the thickness direction. As the thickness of the substrate was $800 \mu \mathrm{m}$, the distance $z$ of the coating layer/substrate interface was taken to be $400 \mu \mathrm{m}$, and the distance $z$ was taken to be $400 \mu \mathrm{m}+T(=10 \mu \mathrm{m}$ in the present sample $)$ at the surface of the coating layer. For this analysis, the crack spacing in the $x$-direction $L=40 \mu \mathrm{m}$, and that in the $y$-direction $W=80 \mu \mathrm{m}$ were used, where $W=80 \mu \mathrm{m}$ corresponds to the thermally induced critical crack spacing in the coating layer, ${ }^{9,10)}$ and $L=40 \mu \mathrm{m}$ corresponds to the critical length at which buckling behavior of the coating layer were observed.

To describe the interfacial debonding of the brittle material with finite element method, spring elements were commonly used. In the present work, we used spring elements which are fractured at certain stress and don't work after their fracture. The critical stress to cause the fracture of the spring elements was regarded as the interfacial bonding strength. In the present analysis, it was taken to be $100 \mathrm{MPa}$ for all coats in Case I and for coat (i) in Case II, as in our

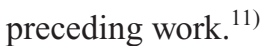

The finite element mesh for the present analysis is shown in Fig. 3(b). In Case I, the bonding strength $100 \mathrm{MPa}$ was used for coat (i) (=coat (iii)) and coat (ii), respectively. In Case II, the bonding strength $100 \mathrm{MPa}$ was commonly used for coat (i) (=coat (iii)) and the bonding strength 60 and $80 \mathrm{MPa}$ were used for coat (ii). In the calculation, the group-buckling process was assumed to occur in the sequence in which (i) a piece of cracked-coating exhibits buckling first and (ii) such a preceding buckling enhance the bucking of the neighboring coating in the sample width direction, as mentioned above.

The present specimens had been heated at $773 \mathrm{~K}$ for formation of the intermetallic compounds and cooled down to

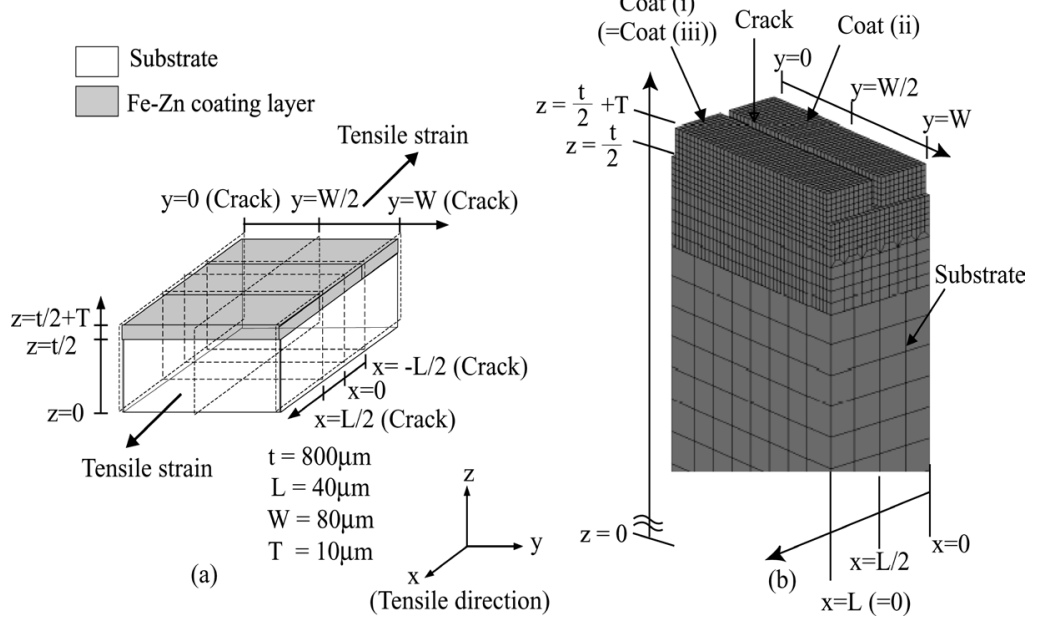

Fig. 3. FEM-mesh of the GA steel for the group-buckling analysis. 
room temperature. Therefore the temperature change $\Delta T=$ $-475 \mathrm{~K}$ was input in order to incorporate the residual stress. In the calculation, the tensile strain was applied from 0 to $10 \%$ in the $x$-direction.

The analysis was carried out with the commercial finite element code MARC/Mentat2003. The Young's modulus, shear modulus, Poisson's ratio and coefficient of thermal expansion of the steel substrate were taken to be 210 $\mathrm{GPa},{ }^{12)} 81 \mathrm{GPa}, 0.30^{12)}$ and $2.2 \times 10^{-5} / \mathrm{K}^{13,14)}$ respectively. ${ }^{15)}$ Those of the coating layer were taken to be $140 \mathrm{GPa},{ }^{12}$ ) $54 \mathrm{GPa}, 0.30^{12)}$ and $1.1 \times 10^{-5} / \mathrm{K},{ }^{13,14)}$ respectively, as similarly as in our preceding works. ${ }^{9-11)}$ It has been known that the coating layer is composed mainly of the $\zeta, \delta_{1}, \Gamma_{1}$ and $\Gamma$ phases and $\delta_{1}$ phase is the thickest under the usual fabrication route. ${ }^{12,15)}$ In the present samples, the volume fraction of the $\delta_{1}$ phase was estimated to be $70-80 \%$ from the composition image of the polished side surface. Concerning the elastic constants $(E, v$ and $G)$, no data have been reported for the $\zeta, \Gamma_{1}$ and $\Gamma$ phases. Only the values for the $\delta_{1}$ phase $^{13)}$ are available. Due to these reasons, the elastic constants of the $\delta_{1}$ phase, which occupies $70-80 \%$ of the coating layer and therefore practically governs the deformation of the coating layer, were used as an approximation. With these values, the multiple cracking behavior of the GA coating layer, observed experimentally, has been described well. ${ }^{9,10)}$

The true stress $(\sigma)$-true plastic strain $\left(\varepsilon_{\mathrm{p}}\right)$ curve of the present steel substrate has been measured in our former work, ${ }^{9,10)}$ which is expressed by,

$$
\sigma=130+400 \varepsilon_{\mathrm{p}}^{0.38}
$$

The yielding condition for the steel substrate was given by the von Mises criterion.

\section{Results and Discussion}

\subsection{Morphology Observation Result}

SEM image and schematic representation of the groupbuckling behavior of the coating layer are shown in Fig. 4. The coatings surround by circles refer to the group buckling.

The possible process of the group-buckling inferred from the present observation is twofold; (a) the buckling of all coatings occurs at one time and (b) the buckling of coatings occurs consecutively along the tensile direction. Based on these observation results, the finite element models mentioned in Sec. 2.2 were prepared.

In our recent research, the grain sizes of the substrate steel were measured experimentally. The grain size of the present sample was $10.3 \mu \mathrm{m}$ in on average, ${ }^{16)}$ and its standard deviation was $5.3 \mu \mathrm{m} .{ }^{16)}$ As shown in Fig. 4, the group-buckling reached more than $100 \mu \mathrm{m}$ long in the tensile direction. This suggests that the group-buckling is not caused by the mismatch of the slip system of the substrate grain.

This group-buckling phenomenon doesn't apply only to GA steels. Similar group-buckling of the coatings in the brittle coating-ductile substrate composite systems was also observed in $\mathrm{Al}_{2} \mathrm{O}_{3}$-coated aluminum wire, as shown in Fig. 5.

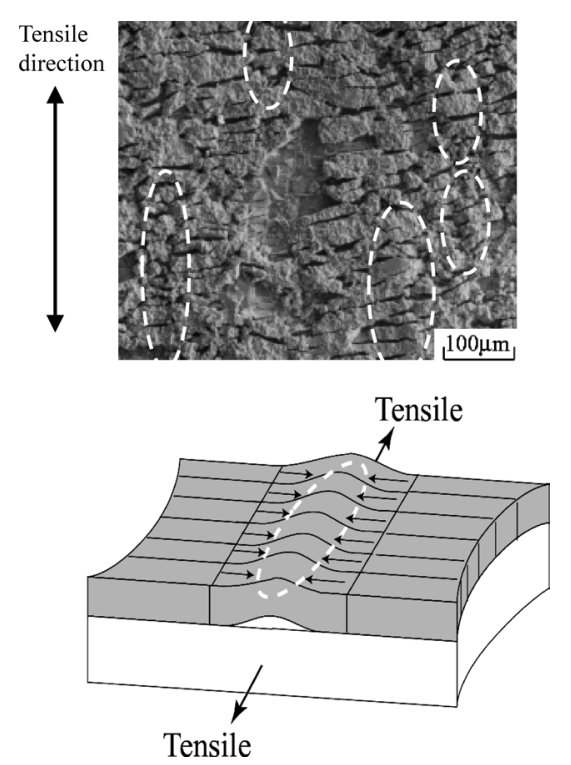

Fig. 4. SEM image and schematic representation of the groupbuckling behavior of the coatings.

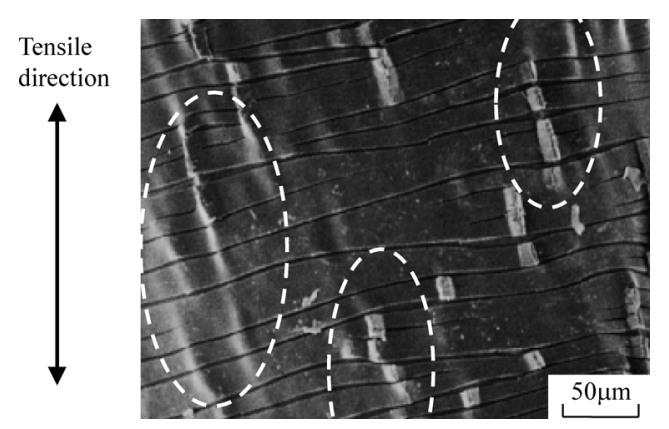

Fig. 5. SEM image of the group-buckling behavior observed in $\mathrm{Al}_{2} \mathrm{O}_{3}$-coated aluminum wire.

\subsection{Results of the Finite Element Analysis}

Figures 6 and 7 show the calculated distribution of the interfacial debonding distance from the substrate to coats (i) and (ii), respectively, under the condition of the bonding strength of coat (i) $\sigma_{\text {(i),int. }}=100 \mathrm{MPa}$ and that of coat (ii) $\sigma_{\text {(ii),int. }}=($ a) $60 \mathrm{MPa}$, (b) $80 \mathrm{MPa}$ and (c) $100 \mathrm{MPa}$. The $x$-, $y$ and $z$-axes in Figs. 6 and 7 show the coordinates indicated in the coating layer (Fig. 3). The distribution of the interfacial debonding distance from the substrate to coatings in the $z$-direction is shown with color.

The debonding distance from substrate to coating was maximum at $x=L / 2$ and $y=W / 2$ for all calculation results. The interfacial stress is highest at $x=L / 2$ and $y=W / 2$ since the difference in amount of deformation between the coat and substrate is largest. Accordingly, the debonding occurs first at $x=L / 2$ and $y=W / 2$ and then extends into the middle. The debonded part moves upward rapidly since the constraint from the substrate has vanished. As the result, the shape of the coat becomes like a horse saddle. Details of the numerical results will be shown in Figs. 8 and 9.

As shown in Fig. 7, the lower the bonding strength $\sigma_{\text {(ii),int. }}$, the larger became the interfacial debonding distance of coat (ii). Meanwhile, the results shown in Fig. 6 revealed that the debonding distance of coat (i) became larger for low bonding strength of coat (ii)-substrate interface $\sigma_{\text {(ii),int. }}$, 


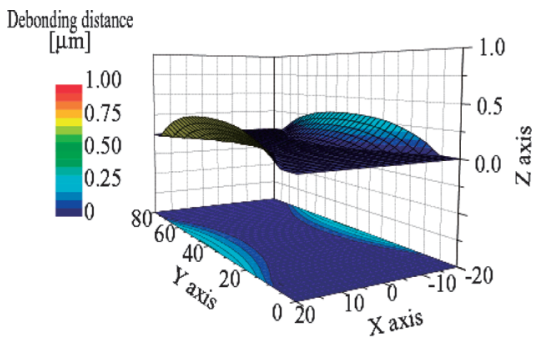

(a)

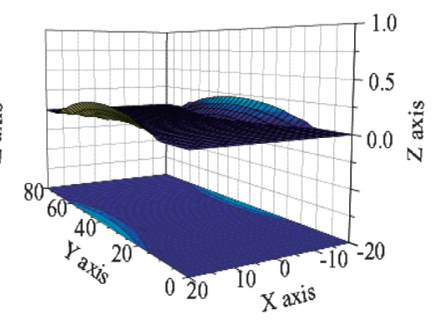

(b)

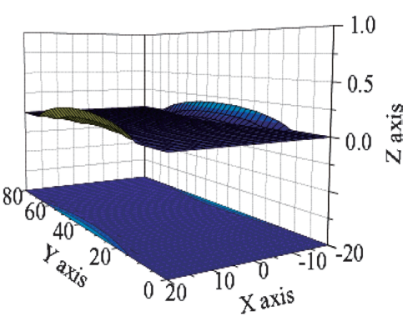

(c)

Fig. 6. Calculated distributions of the interfacial debonding distance from the substrate to coat (i) at $5 \%$ tensile strain in the $x$-direction under the condition of $\sigma_{(\mathrm{i}) \text {,int. }}=100 \mathrm{MPa}$ and $\sigma_{(\mathrm{ii}) \text {,int. }}=$ (a) $60 \mathrm{MPa}$, (b) $80 \mathrm{MPa}$ and (c) $100 \mathrm{MPa}$.

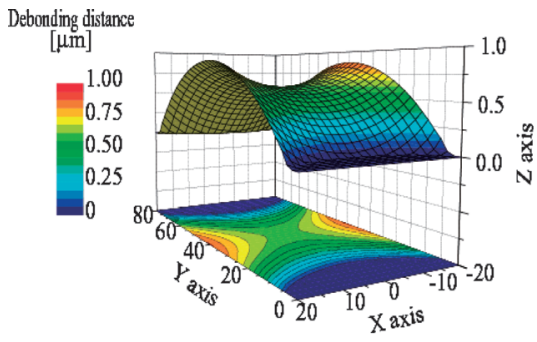

(a)

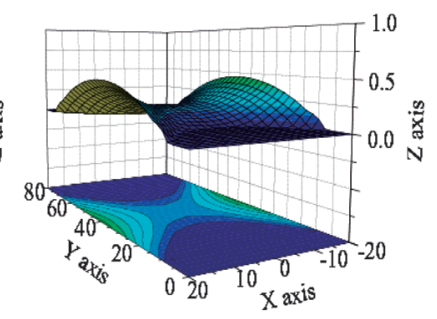

(b)

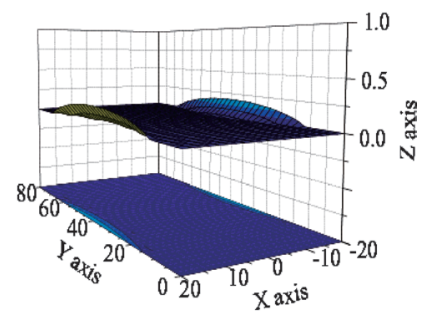

(c)

Fig. 7. Calculated distributions of the interfacial debonding distance from the substrate to coat (ii) at $5 \%$ tensile strain in the $x$-direction under the condition of $\sigma_{\text {(i),int. }}=100 \mathrm{MPa}$ and $\sigma_{\text {(ii),int. }}=$ (a) $60 \mathrm{MPa}$, (b) $80 \mathrm{MPa}$ and (c) $100 \mathrm{MPa}$.

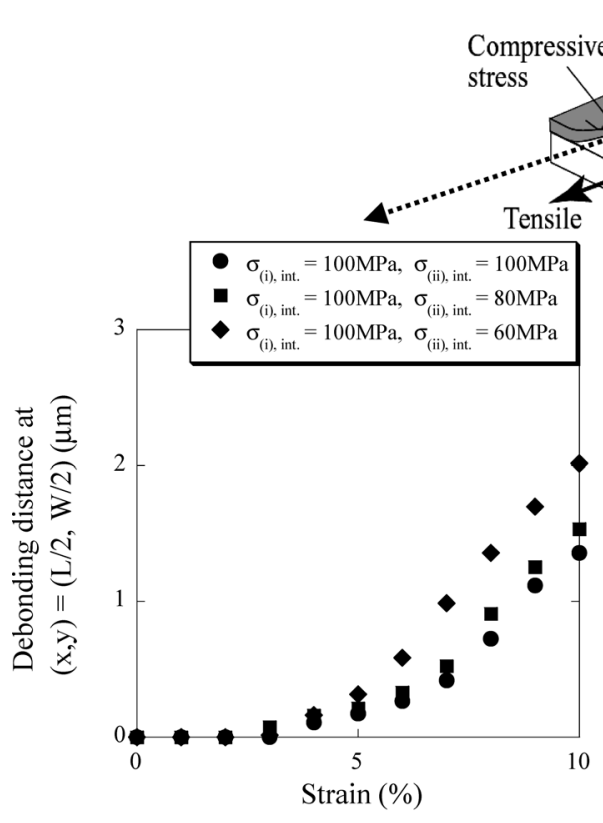

(a)

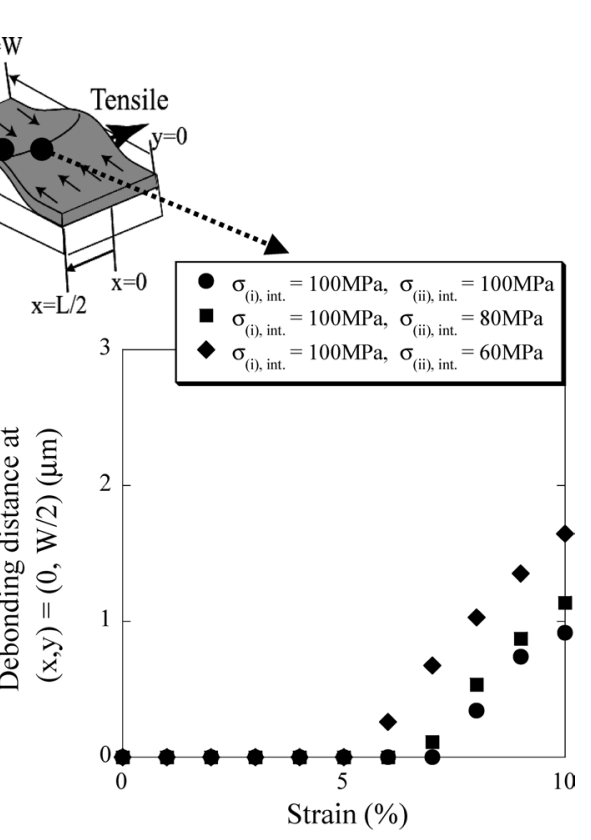

(b)

Fig. 8. Calculated change of the debonding distance at $(x, y)=(L / 2, W / 2)$ (a) and $(0, W / 2)$ (b) for coat (i) under the condition of $\sigma_{(\mathrm{i}) \text {,int. }}=100 \mathrm{MPa}$ and $\sigma_{(\mathrm{ii)}) \text {,int. }}=60 \mathrm{MPa}, 80 \mathrm{MPa}$ and $100 \mathrm{MPa}$.

although the bonding strength in coat (i) $\sigma_{(\mathrm{i}) \text { int }}$ was same $\left(\sigma_{(\mathrm{i}) \text {,int. }}=100 \mathrm{MPa}\right)$. That is, the group-buckling occurs, originating from the buckling of the coating with weak interface, coat (ii) in the present analysis.

Figures 8 and 9 shows the change of the debonding distance at $(x, y)=(L / 2, W / 2)$ and $(0, W / 2)$ with applied tensile strain for coat (i) and coat (ii). The position $(x, y)=$ $(L / 2, W / 2)$ corresponded to the position getting the maximum value of the debonding distance. The position $(x, y)=$ $(0, W / 2)$ corresponded to the center of the coating which is important to evaluate the progression of interfacial debonding.

As shown in Fig. 9, the lower the bonding strength of the coat (ii)-substrate interface $\sigma_{(\mathrm{ii)}) \text {,int. }}$, the larger became the debonding distance of coat (ii) at both $(x, y)=(L / 2, W / 2)$ and $(0, W / 2)$.

As shown in Fig. 8, the debonding distance at both $(x, y)=(L / 2, W / 2)$ and $(0, W / 2)$ in coat (i) also became larger with low bonding strength of the coat (ii)-substrate interface $\sigma_{(\mathrm{ii}) \text {,int. }}$. In addition, the applied strain at which the in- 


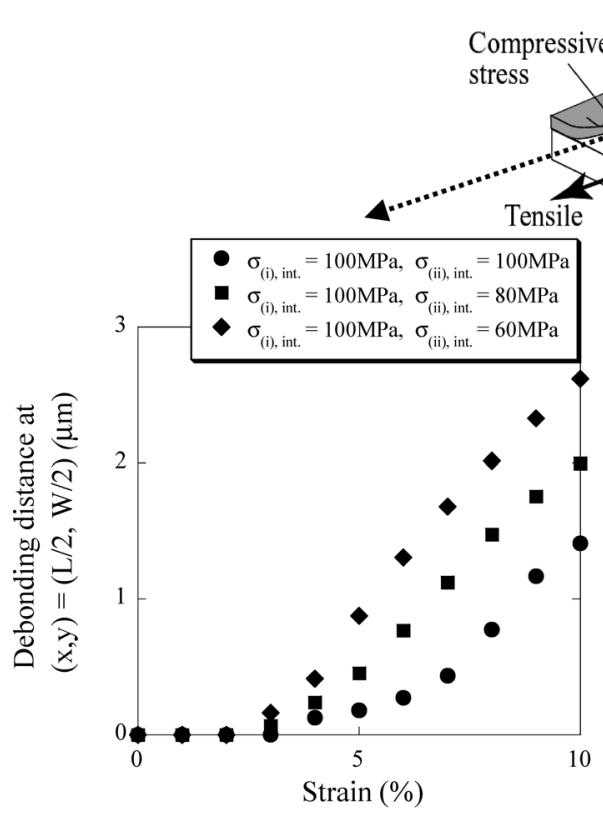

(a)

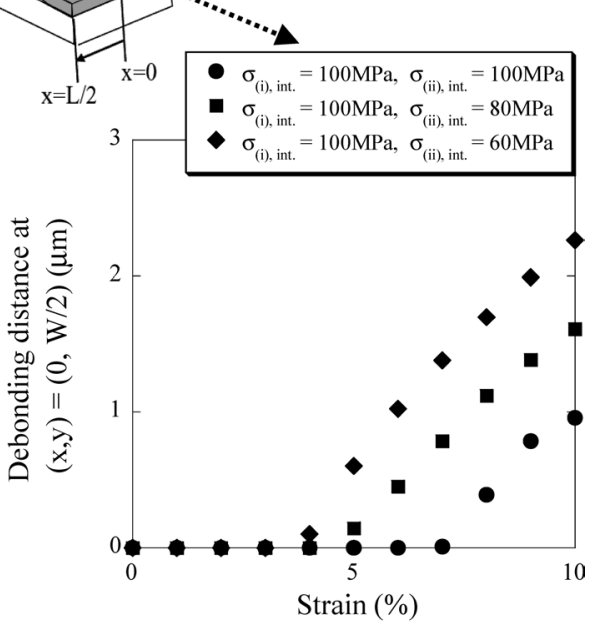

(b)

Fig. 9. Calculated change of the debonding distance at $(x, y)=(L / 2, W / 2)$ (a) and $(0, W / 2)$ (b) for coat (ii) under the condition of $\sigma_{(\mathrm{i}) \text {,int. }}=100 \mathrm{MPa}$ and $\sigma_{(\mathrm{ii}) \text {,int. }}=60 \mathrm{MPa}, 80 \mathrm{MPa}$ and $100 \mathrm{MPa}$.
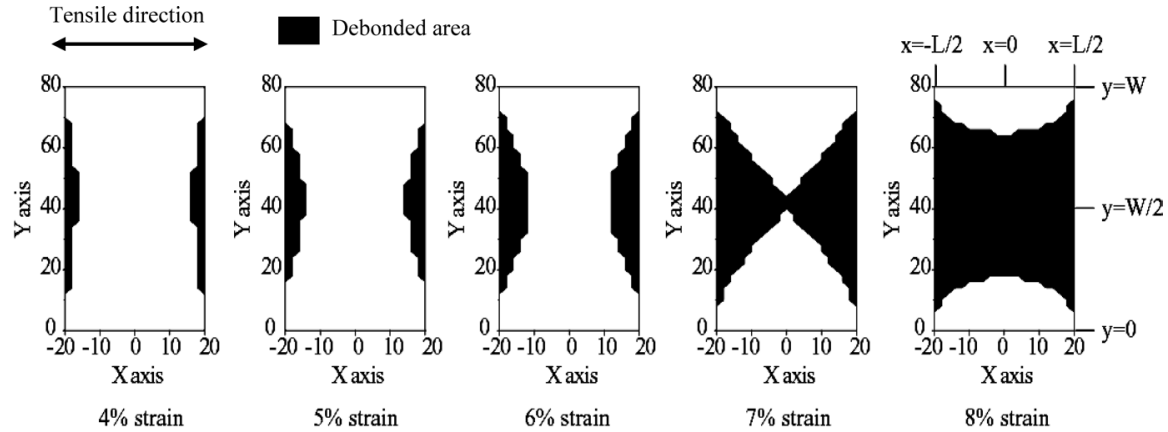

(a)
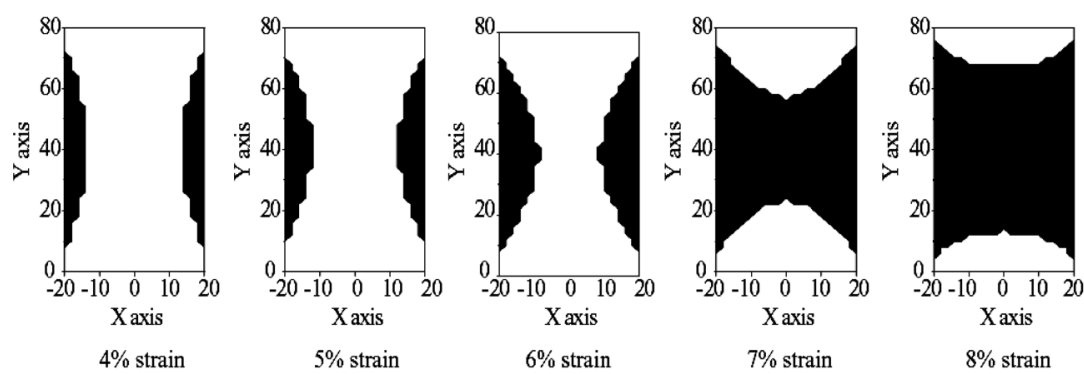

(b)
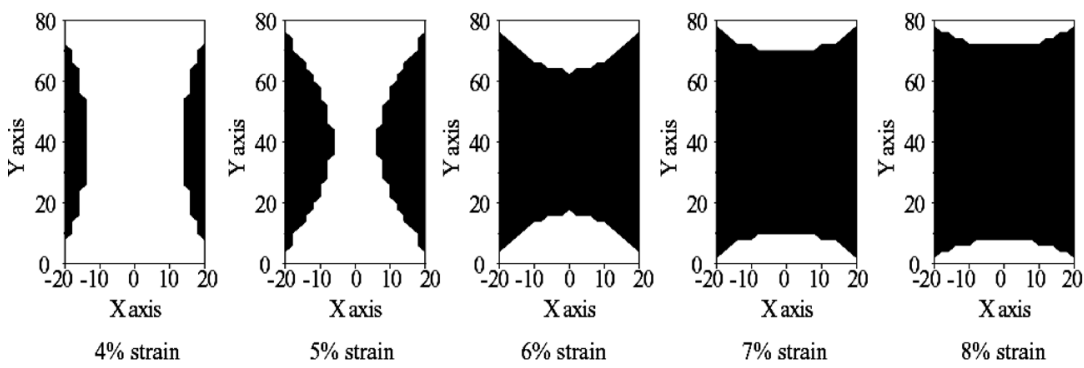

(c)

Fig. 10. Progress of the debonded area of the coat (i)-substrate interface with increasing applied strain, under the condition of $\sigma_{(\mathrm{i}) \text {,int. }}=100 \mathrm{MPa}$ and $\sigma_{(\mathrm{ii}) \text {,int. }}=(\mathrm{a}) 100 \mathrm{MPa}$, (b) $80 \mathrm{MPa}$ and (c) $60 \mathrm{MPa}$. 

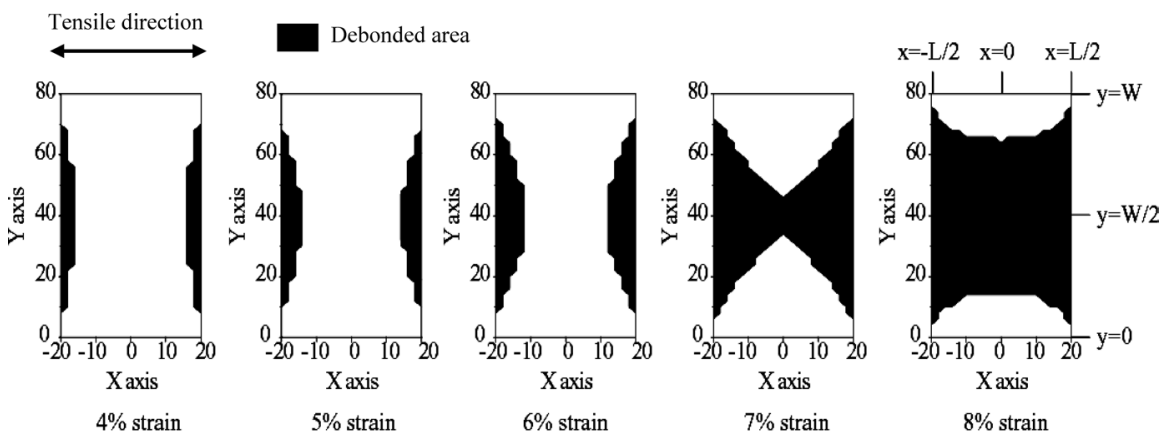

(a)
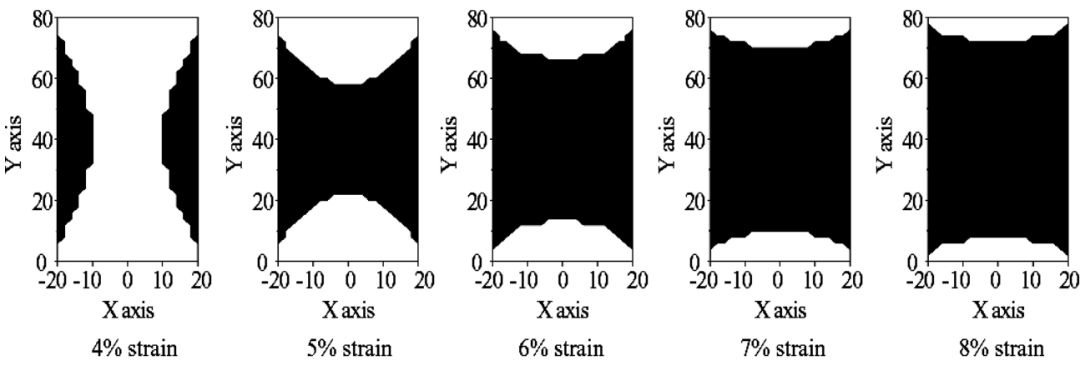

(b)
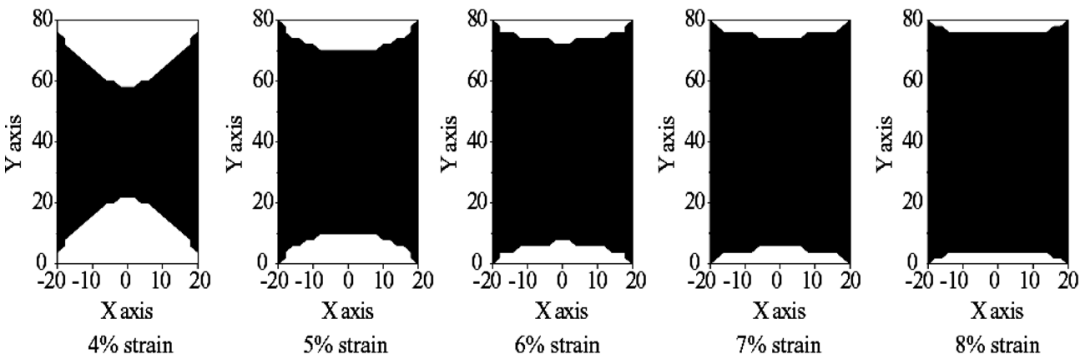

(c)

Fig. 11. Progress of the debonded area of the coat (ii)-substrate interface with increasing applied strain, under the condition of $\sigma_{(\mathrm{i}) \text {,int. }}=100 \mathrm{MPa}$ and $\sigma_{(\mathrm{ii}) \text {,int. }}=$ (a) $100 \mathrm{MPa}$, (b) $80 \mathrm{MPa}$ and (c) $60 \mathrm{MPa}$.

terfacial debonding started became lower with low bonding strength of coat (ii) $\sigma_{\text {(ii),int. }}$ at $(x, y)=(0, W / 2)$ in coat (i), as shown in Fig. 8(b). From this result, it is expected that the debonding of coat (ii) affected not only on the maximum debonding distance of coat (i) but also the progression of interfacial debonding of coat (i).

From the comparison of the Fig. 8 and Fig. 9, it was found that the debonding distance of coat (ii) was not directly reflected in that of coat (i). As shown in Fig. 8, the debonding distance of the coat (i) under the condition of $\sigma_{\text {(ii),int. }}=100 \mathrm{MPa}$ was only slightly smaller than that under the condition of $\sigma_{(\mathrm{ii}) \text {,int. }}=80 \mathrm{MPa}$, in contrast to the debonding distance of the coat (ii) which was much larger under the condition of $\sigma_{\text {(ii),int. }}=80 \mathrm{MPa}$.

The progress of the debonded area of the coat (i)-substrate interface and coat (ii)-substrate interface with increasing applied strain, under the condition of $\sigma_{(\mathrm{i}) \text {,int. }}=$ $100 \mathrm{MPa}$ and $\sigma_{\text {(ii),int. }}=(\mathrm{a}) 100 \mathrm{MPa}$, (b) $80 \mathrm{MPa}$ and (c) $60 \mathrm{MPa}$, are shown in Figs. 10 and 11, respectively. The debonded part of the coating is shown in black color in Figs. 10 and 11. As shown in Fig. 10(a), the debonded area progressively increases from the edge $(x, y)=(L / 2, W / 2)$, and rapidly progresses in the $y$ direction after the debonding at the center $(x, y)=(0, W / 2)$.
Figure 12 shows the change of the occupancy of the debonded area (=ratio of the debonded area (shown in block color in Figs. 10 and 11) to the whole area of the interface) with applied tensile strain for coat (i) (a) and (ii) (b). The lower the bonding strength, the larger became the occupancy of the debonded area of the coat (ii)-substrate interface, as shown in Fig. 12(b). For the coat (i)-substrate interface, as shown in Fig. 12(a), the occupancy of the debonded area also became larger for low bonding strength of the coat (ii)-substrate interface $\sigma_{(\text {ii),int. }}$.

As indicated in Figs. 8 and 12(a), the preceding debonding of the coating with low interfacial bonding strength enhances the interfacial debonding of the neighboring coating. In this way, the group-buckling phenomenon in the galvannealed coatings was accounted for by the mechanical viewpoint under the scattered interfacial bonding strength. This is the first approach to make clear the mechanism of group-buckling using numerical analysis.

As mentioned above, similar group-buckling behaviors were also observed in $\mathrm{Al}_{2} \mathrm{O}_{3}$-coated aluminum wire. It is possible that the mechanism of group-buckling is universally applied for all brittle coating composite, not only galvannealed steel, by the present mechanical approach. 


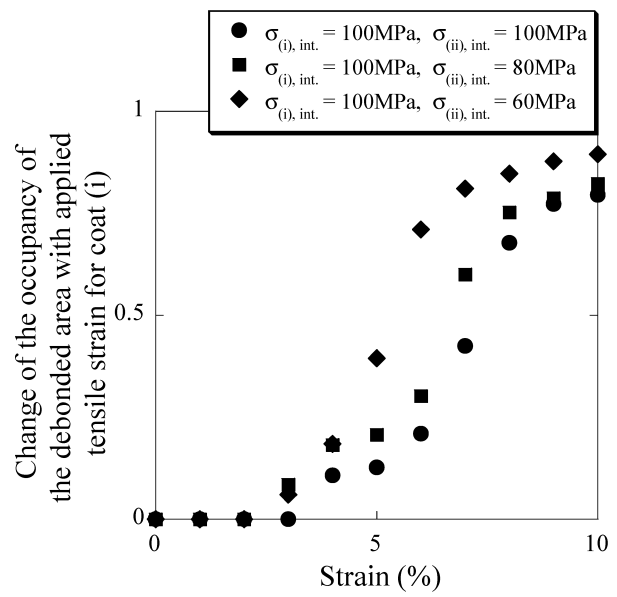

(a)

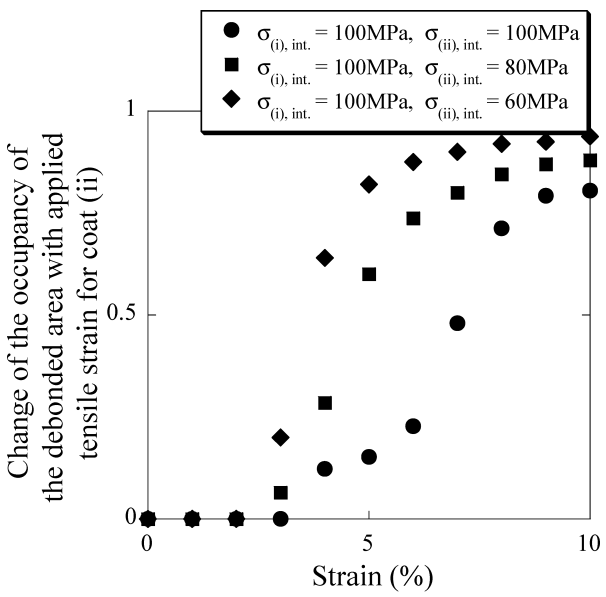

(b)

Fig. 12. Change of the occupancy of the debonded area with applied tensile strain for coat (i) (a) and coat (ii) (b).

\section{Conclusions}

(1) The observation of the specimens revealed that the galvannealed coating layer on steel substrate exhibits the group buckling/interfacial debonding under applied tensile strain, and the group-buckling is not caused by the buckling at one time upon the mismatch of the slip system of the substrate grain from the comparison between the grain size of substrate steel and the length of the group-buckled coatings.

(2) The finite element stress analysis revealed that the debonding distance of coat (i) becomes larger for low interfacial bonding strength between coat (ii) and substrate. This means that the group-buckling occurs, originating from the buckling of the coating with weak interfacial bonding.

(3) At the center of the coating, the applied strain at the onset of the interfacial debonding becomes lower for low interfacial bonding strength of the corresponding and neighboring coatings. The occupancy of the debonded area also becomes larger for low interfacial bonding strength of the corresponding and neighboring coatings.

(4) Similar group-buckling behavior was also observed in $\mathrm{Al}_{2} \mathrm{O}_{3}$-coated aluminum wire. The mechanical approach developed in this work is applicable not only to galvannealed steel but also to brittle coating composites for analysis of the group-buckling.

\section{Acknowledgement}

The authors wish to express their gratitude to Japan Soci- ety for the Promotion of Science for Young Scientists and to The Iron and Steel Institute of Japan for the support of the present work.

\section{REFERENCES}

1) C. E. Jordan CE, K. M. Goggins and A. R. Marder: Metall. Mater. Trans. A, 25A (1994), 2101.

2) S. Lazik, C. Esling and J. Wegria: Textures Microstruct., 23 (1995), 131.

3) A. Kelly A and W. R. Tyson: J. Mech. Phys. Solids, 13 (1965), 329.

4) S. Ochiai and K. Osamura: J. Mater. Sci., 21 (1986), 2735.

5) M. S. Hu and A. G. Evans: Acta Metall., 37 (1989), 917.

6) Y. Leterrier, L. Boogh, J. Andersons and J.-A. E. Mason: J. Polym. Sci. B, Polym. Phys., 35 (1997), 1449.

7) S. Ochiai and Y. Murakami: Met. Sci., 41 (1976), 401.

8) J. Andersons, U. A. Handge, I. M. Sokolov and B. Blumen: Eur. Phys. J., B17 (2000), 261.

9) S. Iwamoto, S. Ochiai, T. Nakamura and H. Okuda: Tetsu-toHagané, 91 (2005), 335.

10) S. Ochiai, S. Iwamoto, T. Tomida, T. Nakamura, H. Okuda, M. Tanaka and H. Hojo: Metall. Mater. Trans. A, 36A (2005), 1807.

11) S. Iwamoto, S. Ochiai, H. Okuda and T. Inoue: ISIJ Int., 47 (2007), 930.

12) G. Reumont, J. B. Vogt, A. Iost and J. Foct: Surf. Coat. Technol., 139 (2001), 265

13) J. Foct: Scr. Metall. Mater, 28 (1993), 127.

14) A. Iost and J. Foct: J. Mater. Sci., 12 (1993), 1340.

15) E. Tzimas and G. Papadrimitriou: Surf. Coat. Technol., 145 (2001), 176.

16) T. Nakamura, S. Ochiai, S. Iwamoto, D. Adachi and H. Okuda: Tetsu-to-Hagané, 91 (2005), 342. 